Article

\title{
Lumped Parameter Model and Electromagnetic Performance Analysis of a Single-Sided Variable Flux Permanent Magnet Linear Machine
}

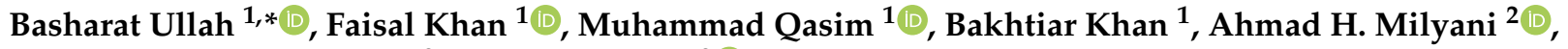 \\ Khalid Mehmood Cheema ${ }^{3}$ and Zakiud Din ${ }^{3}$ (D)
}

1 Department of Electrical and Computer Engineering, COMSATS University Islamabad, Abbottabad 22060, Pakistan; faisalkhan@cuiatd.edu.pk (F.K.); qasimrajput217@gmail.com (M.Q.); engr.bakhtiarkhan@gmail.com (B.K.)

2 Department of Electrical and Computer Engineering, King Abdulaziz University, Jeddah 21589, Saudi Arabia; ahmilyani@kau.edu.sa

3 School of Electrical Engineering, Southeast University, Nanjing 210096, China;

kmcheema@seu.edu.cn (K.M.C.); zaki@seu.edu.cn (Z.D.)

* Correspondence: basharat.bigb@gmail.com

\section{check for}

updates

Citation: Ullah, B.; Khan, F.; Qasim, M.; Khan, B.; Milyani, A.H.; Cheema, K.M.; Din, Z. Lumped Parameter Model and Electromagnetic

Performance Analysis of a

Single-Sided Variable Flux Permanent Magnet Linear Machine. Energies 2021, 14, 5494. https://doi.org/ $10.3390 /$ en14175494

Academic Editors: Ryszard Palka and Marcin Wardach

Received: 6 August 2021

Accepted: 30 August 2021

Published: 3 September 2021

Publisher's Note: MDPI stays neutral with regard to jurisdictional claims in published maps and institutional affiliations.

Copyright: (C) 2021 by the authors Licensee MDPI, Basel, Switzerland. This article is an open access article distributed under the terms and conditions of the Creative Commons Attribution (CC BY) license (https:/ / creativecommons.org/licenses/by/ $4.0 /)$.

\begin{abstract}
A new Single-sided Variable Flux Permanent Magnet Linear Machine with flux bridge in mover core is proposed in this paper. The flux bridge prevents the leakage flux from the mover and converts it into flux linkage, which greatly influences the performance of the machine. First, a lumped parameter model is used to find the suitable coil combination and no-load flux linkage of the proposed machine, which greatly reduces the computational time and drive storage. Secondly, the proposed machine replaces the expensive rare earth permanent magnets with ferrite magnets and provides improved flux controlling capability under variable excitation currents. Multivariable geometric optimization is utilized to optimize the leading design parameters like split ratio, stator pole width, width and height of permanent magnet, flux bridge width, the width of mover's tooth, and stator slot depth at constant electric and magnetic loading. The optimized design increases the flux linkage by $44.11 \%$, average thrust force by $35 \%$, thrust force density by $35.02 \%$, minimizes ripples in thrust force by $23 \%$, and detent force by $87.5 \%$. Furthermore, the results obtained by $2 \mathrm{D}$ analysis are verified by $3 \mathrm{D}$ analysis. Thermal analysis is done to set the operating limit of the proposed machine.
\end{abstract}

Keywords: finite element analysis; flux switching machine; flux bridge; magnetic flux leakage; variable flux machine

\section{Introduction}

Due to simple and robust structure, linear flux switching permanent magnet machines (LFSPMMs) have been widely researched over the past few years [1-4]. In LFSPMM, the short mover carries all the excitation sources leaving the secondary completely robust, which makes it a prominent candidate for long stroke applications $[1,5]$. Since LFSPMMs possess high power density, faster dynamic response [6], high thrust force density [7], bipolar flux linkage [8] and good overload capability [9], they have been widely used in many applications from household appliances to transportation [2,10,11]. However, LFSPMM has some related disadvantages, especially the difficulty of adjusting the magnetic field, which is undesirable for applications that require flexible magnetic flux control or having a wide speed range [12].

Unfortunately, the prices of rare earth permanent magnet (PM) materials (such as dysprosium, neodymium, and terbium) have been rising for the past decade, which in turn increases the overall cost of the machine. In order to reduce the manufacturing cost of the machine, rare earth PMs are replaced by ferrite magnets in the design proposed in this 
paper. To further lower the cost of the machine, overcome the aforementioned problems associated with LFSPMM, and achieve the flux regulation capability, another solution is Variable Flux Switching Machines i.e., Field Excited LFSM (FELFSM) and Hybrid Excited LFSM (HELFSM). LFSPMMs have only armature excitation (AE) and PMs. FELFSMs have both AE and field excitation (FE) [13]. Since FELFSM avoids the use of PM, it has the advantage of better controllability of flux and is cost effective [14], but it possesses an extensive downside of low thrust force density with weak flux linkage [15]. While HELFSMs have all the three excitation sources i.e., AE, PMs, and FE. PM along with FE becomes the main source of flux in HELFSM [16]. Compared to LFSPMM machines HELFSM has higher efficiency, higher thrust force density, and better controllability of flux [17]. Based on the field flux traveling path, HELFSMs can be further classified into series or parallel hybrid-excited ones. According to the placement of PMs and FE various HELFSM have been proposed [18-20]. In [18] a new type of HELFSM is proposed and studied based on the rotary hybrid excited flux switching machine proposed in [21]. In [18] the authors replaced the rare earth PMs with ferrite magnets and additional FE windings were used to obtain better flux regulation. This proposed design is then converted into double-sided HELFSM [16]. In [22], three different models of a hybrid excited FSM with FE coils located in stator slots are proposed and investigated. In [23] three HELFSM are proposed based on PM placement at the bottom, middle, and top, respectively. The analysis revealed that the bottom PM machine shows the best magnet utilization and flux adjustment capability. All the excitation sources are placed on a short mover so the area of field slot, armature slot, and PM will compete with each other, thereby, affecting the electromagnetic performance of the machine [24-26]. However, this issue is not that significant if appropriate effective parameters, proper electric and magnetic loadings are selected, to meet the desired performance.

In this paper, a new Single-sided Variable Flux Permanent Magnet Linear Machine (VFPMLM) with flux bridge in mover core is proposed. The proposed design replaces the expensive rare-earth PMs with ferrite magnets, uses FE for better field weakening capability. VFPMLM offers high thrust force density, high thrust force per PM volume, with much lower copper losses than the conventional design in the literature, and is preferred for long stroke applications.

The rest of the paper is organized as, Section 2 presents the machine topology and its operating principle, in Section 3 no load flux linkage is obtained through lumped parameter model, in Section 4 various performance analysis parameters are discussed, in Section 5 geometric optimization is utilized to analyze the influence of different design parameters on the performance of the machine, the electromagnetic performance of the machine is analyzed, and compared in Sections 6 and 7 concludes the paper.

\section{Machine Topology and Operating Principle}

\subsection{Machine Topology}

The topology of the single-sided VFPMLM is shown in Figure 1, and Figure 2 shows the corresponding design variables. Table 1 enlists the values of leading design parameters. All the excitation sources are installed on the mover, while the stator is completely passive. The proposed single-sided VFPMLM has concentrated three-phase armature windings, each coil set is composed of two sets of AE coils. The field winding is overlapping the armature winding. The magnetic flux bridge denoted by $w_{f b}$ in Figure 3 eliminates the flux leakage through the mover, so the magnetic flux passes through the mover core and converts the leakage into a flux linkage. The yoke of the mover and the flux bridge help in flux linkage and distribution through the air gap. This magnetic flux arrangement improves the flux modulation effect of PM and FE, which superimpose each other through the flux bridge and generate higher magnetic flux density, hence improving thrust force generating ability, reducing detent force, force ripples and the PM slot effect. In order to select the number of stator poles Equation (1) is utilized. 


$$
S_{p}=P_{S}\left(2 \pm \frac{n}{2 q}\right)
$$

In (1), $S_{p}$ represents the number stator poles, $P_{S}$ represents the number of mover slots, $q$ denotes the number of phases and $n$ is any natural number. Various values of natural numbers are considered and the performance of the respective pole/slot combination is analyzed. Table 2 enlists all the possible combinations that the machine has a bipolar flux linkage and unipolar thrust force. Thrust force for the $7 / 6$ combination is higher, therefore it is considered for further analysis.

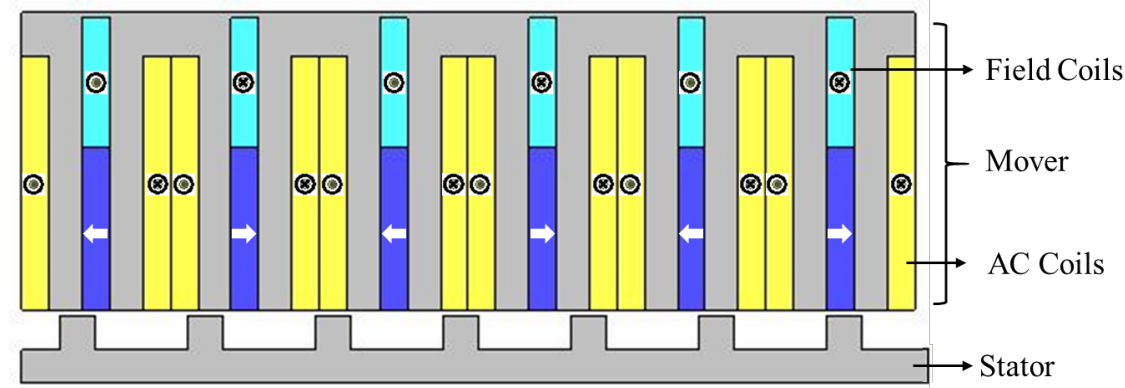

Figure 1. Design of proposed single-sided VFPMLM.

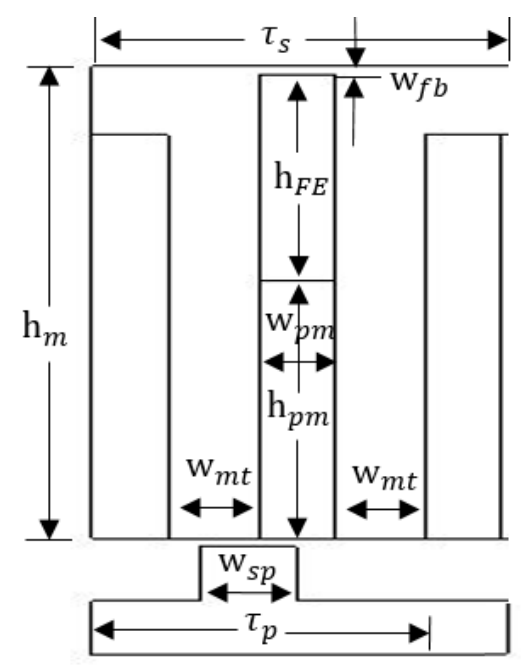

Figure 2. Design parameters of proposed single-sided VFPMLM.

\subsection{Operating Principle}

The operating principle of single-sided VFPMLM is based on no-load magnetic flux (excitation due to PM and FE) linkage achieved by 2D Finite Element Analysis (FEA). The proposed design has a bipolar flux linkage. The magnetic flux generated by the excitation sources at the mover has to flow through the mover's tooth, crosses the air gap, enters stator body through the stator tooth, then exits through the next stator tooth, crosses the air gap again, and enters into the second-mover tooth to link with the armature coil to complete its circuit. 


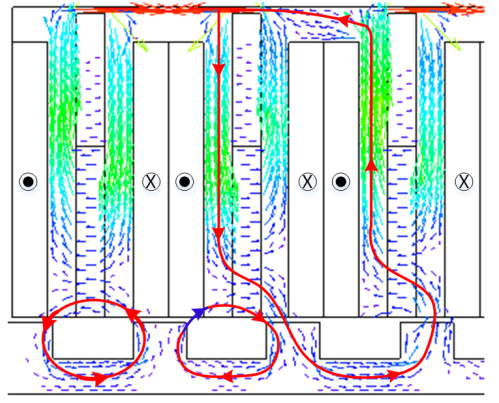

(a)

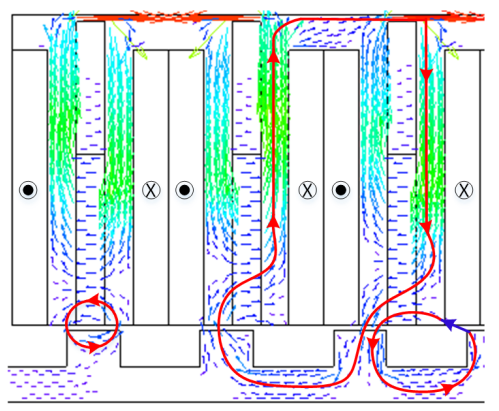

(c)

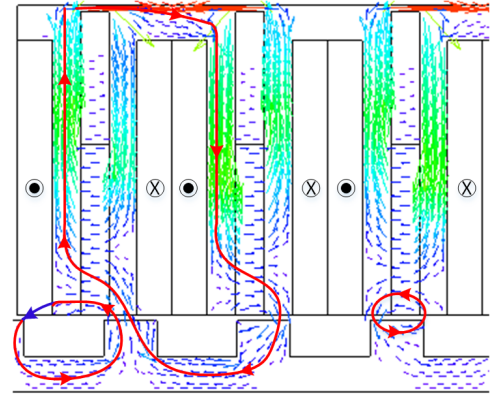

(b)

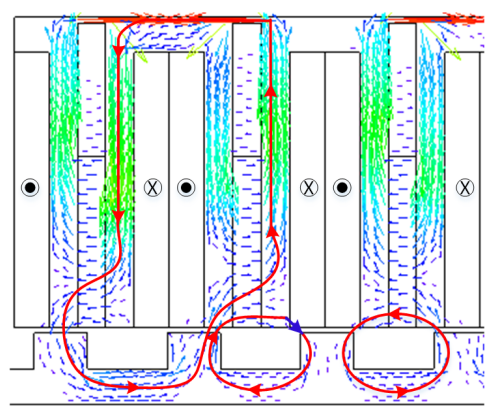

(d)

Figure 3. Principle of operation (a) $\theta=0^{\circ}$ (b) $\theta=90^{\circ}$ (c) $\theta=180^{\circ}$ (d) $\theta=270^{\circ}$.

Table 1. Design parameters of Single-sided VFPMLM.

\begin{tabular}{cccc}
\hline Symbol & Description & Unit & Dimension \\
\hline$h_{m}$ & mover height & $\mathrm{mm}$ & 43.5 \\
$L_{T}$ & whole mover length & $\mathrm{mm}$ & 131 \\
$\tau_{s}$ & mover pole pitch & $\mathrm{mm}$ & 21.84 \\
$h_{A E}$ & AC slot height & $\mathrm{mm}$ & 33.4 \\
$h_{F E}$ & DC slot height & $\mathrm{mm}$ & 19.5 \\
$h_{P M}$ & PM height & $\mathrm{mm}$ & 24 \\
$w_{f b}$ & flux bridge width & $\mathrm{mm}$ & 1 \\
$N_{A E}$ & AC turns & - & 220 \\
$N_{F E}$ & DC turns & - & 50 \\
$v$ & velocity & $\mathrm{m} / \mathrm{sec}$ & 4 \\
$A_{g}$ & air gap & $\mathrm{mm}$ & 0.8 \\
$L$ & stack length & $\mathrm{mm}$ & 90 \\
$\tau_{p}$ & stator pole pitch & $\mathrm{mm}$ & 18.72 \\
$w_{S}$ & Stator pole width & $\mathrm{mm}$ & 8.42 \\
$k_{w}$ & winding filling factor & - & 0.5 \\
$I_{F E}$ & FE current & Amps & 6 \\
\hline
\end{tabular}

Table 2. Different stator poles combination.

\begin{tabular}{ccc}
\hline Pole/Slot Combination & Thrust Force & Detent Force \\
\hline $5 / 6$ & $112.714 \mathrm{~N}$ & $76.59 \mathrm{~N}$ \\
$7 / 6$ & $165.212 \mathrm{~N}$ & $36.05 \mathrm{~N}$ \\
$8 / 6$ & Bipolar Force & - \\
$10 / 6$ & Bipolar Force & - \\
$11 / 6$ & $139.653 \mathrm{~N}$ & $49.01 \mathrm{~N}$ \\
$13 / 6$ & $65.42 \mathrm{~N}$ & $9.53 \mathrm{~N}$ \\
\hline
\end{tabular}


Considering the movement of the mover along the x-axis as shown in Figure 3, when the relative position of the PM is in the center of the stator slot, the electrical angle $(\theta)$ is assumed to be zero degrees. The magnetic flux linkage in coil A is zero at the specified position is shown in Figure 3a, because the flux does not pass through the mover core. At $1 / 4$ th movement of electrical angle $\left(\theta=90^{\circ}\right)$ the flux linkage in coil A is positive maximum because the direction of flux linkage and AE coil direction is same shown in Figure $3 \mathrm{~b}$. After half cycle $\left(\theta=180^{\circ}\right)$ movement of the mover, the magnitude of flux linkage in coil A becomes zero again because the flux does not pass through the mover core as shown in Figure 3c. At 3/4th movement $\left(\theta=270^{\circ}\right)$, the flux linkage in coil A attains a negative maximum because the direction of flux linkage and $\mathrm{AE}$ coil direction becomes opposite shown in Figure 3d. This all can be evident from Figure 4. The operating principle explained is repetitive, and has been verified for all three armature coils.

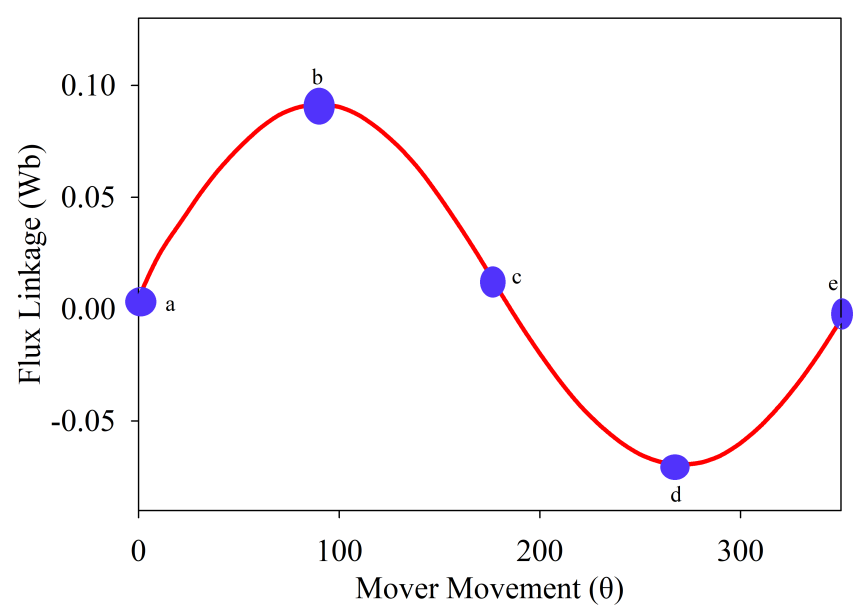

Figure 4. No-load flux linkage.

\section{Lumped Parameter Model}

Lumped parameter model (LPM) is widely used to model all the parts of machine (mover, airgap, stator) [27,28]. In this paper LPM is developed for 1/3rd machine as shown in Figure 5 to reduce the simulation time, drive storage and computational complexity. LPM is based on the following equations.

$$
\begin{gathered}
\phi_{s}=P F \\
F_{p m}=\frac{B_{r} l_{p m}}{\mu_{o} \mu_{r}} \\
F_{F E}=N_{F E} I_{F E} \\
P_{p m}=\frac{\mu_{o} \mu_{r} l_{s t k} w_{p m}}{l_{p m}}
\end{gathered}
$$

The permeance of iron parts can be calculated as:

$$
P_{m y / f b / m t / s t / r c}=\int \frac{\mu_{o} \mu_{r}}{l_{i}} d A_{i}
$$

After calculating the permeance of all parts, and sources at nodes, nodal analysis is employed to calculate flux flowing out and flowing in to the corresponding nodes as:

$$
\left[\begin{array}{c}
\phi_{s}(1) \\
\vdots \\
\phi_{s}(N)
\end{array}\right]=\left[\begin{array}{ccc}
P(1,1) & \cdots & P(1, N) \\
\vdots & \ddots & \vdots \\
P(M, 1) & \cdots & P(M, N)
\end{array}\right]\left[\begin{array}{c}
F(1) \\
\vdots \\
F(N)
\end{array}\right]
$$


$P(M, N)$, the permeance matrix can be written as follows:

$$
P(M, N)=\left\{\begin{array}{l}
1 \text { branch } N \text { begins from node } M \\
0 \quad \text { no connection between branch Nand node } M \\
-1 \quad \text { branch } N \text { ends at node } M
\end{array}\right.
$$

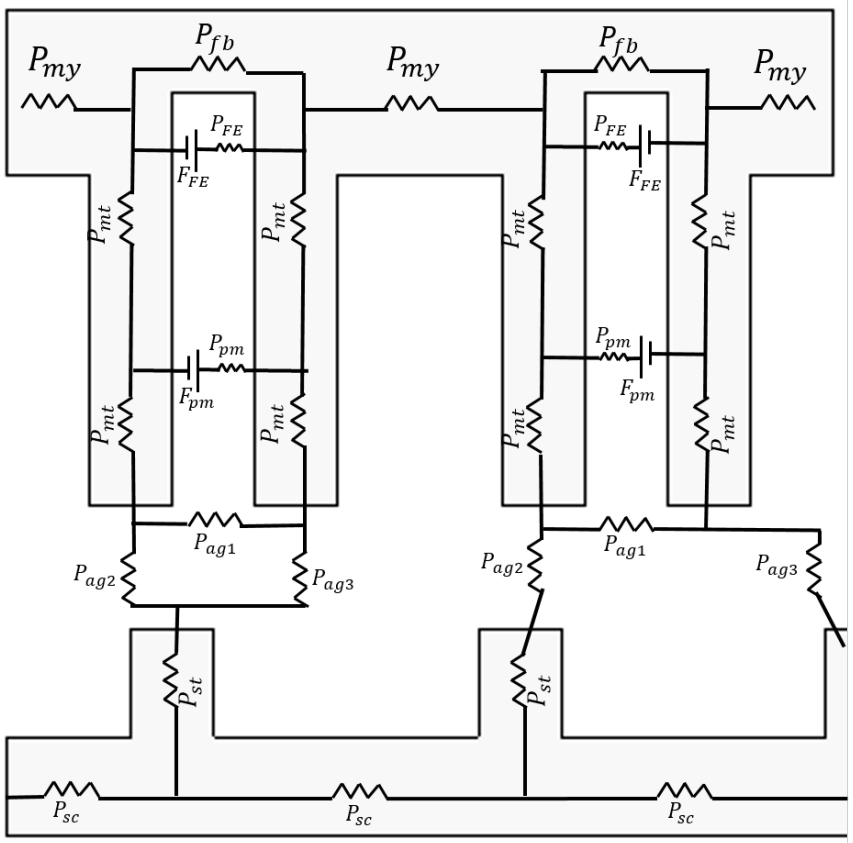

Figure 5. LPM of proposed Single-sided VFPMLM.

Equation (7) is solved in three steps [29], through iterative process to calculate the no-load flux linkage with considering the initial relative permeability of 4000. Firstly, $H_{i}$ in the mover and stator part is calculated using Equation (9). Once $H_{i}$ is calculated, relative permeability is updated using Equation (10). Finally, magnetic flux density (Equation (11)) is calculated using the same iterative process. Figure 6 shows the no-flux linkage obtained by FEA analysis and calculated through LPM. There is a small error between the two but considering computational time, drive storage it is not that significant.

$$
\begin{gathered}
H_{i}^{k-1}=\frac{\Delta F_{i}^{k-1}}{l_{i}} \\
\mu_{r}^{k}=\frac{\left[H_{i}^{k-1}+M_{s}\left(\operatorname{coth}\left(\frac{H_{i}^{k-1}}{\beta}\right)-\frac{\beta}{H_{i}^{k-1}}\right)\right]}{H_{i}^{k-1}} \\
B_{i}^{k}=\frac{\Delta F_{i}^{k} P}{A_{i}}
\end{gathered}
$$

The LPM is validated by JMAG v19.1 and detailed comparison based on computation time and drive storage is given in Table 3 . The LPM greatly reduces the drive storage and computational time as compared to FEA. Both the LPM and FEA were performed on a Lenovo 64-bit operating system with 8 GB RAM and an Intel(R) Core(TM) i5-8500 CPU running at $3.00 \mathrm{GHz}$. 


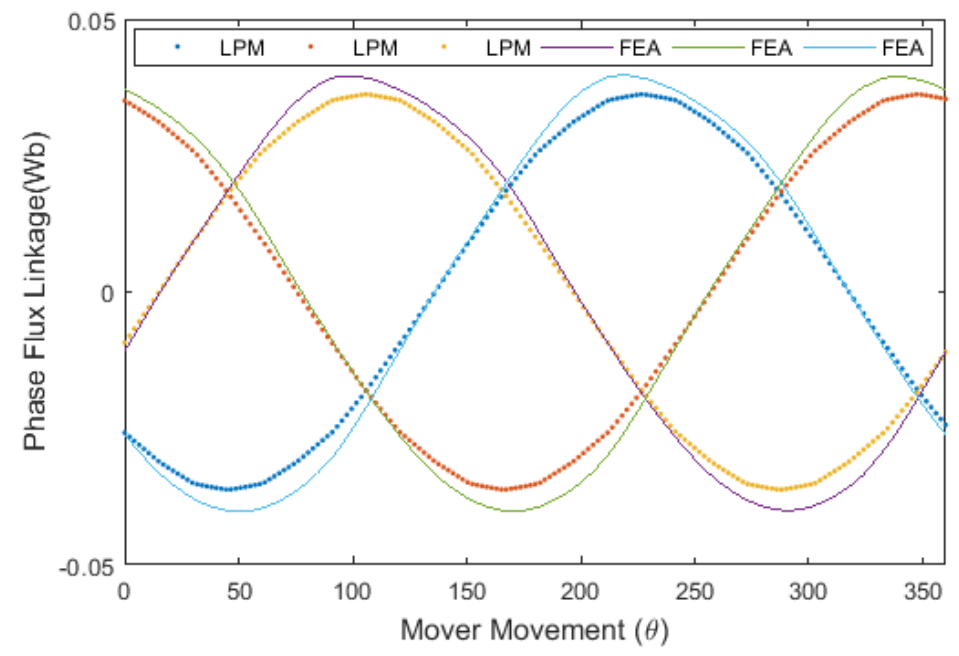

(a)

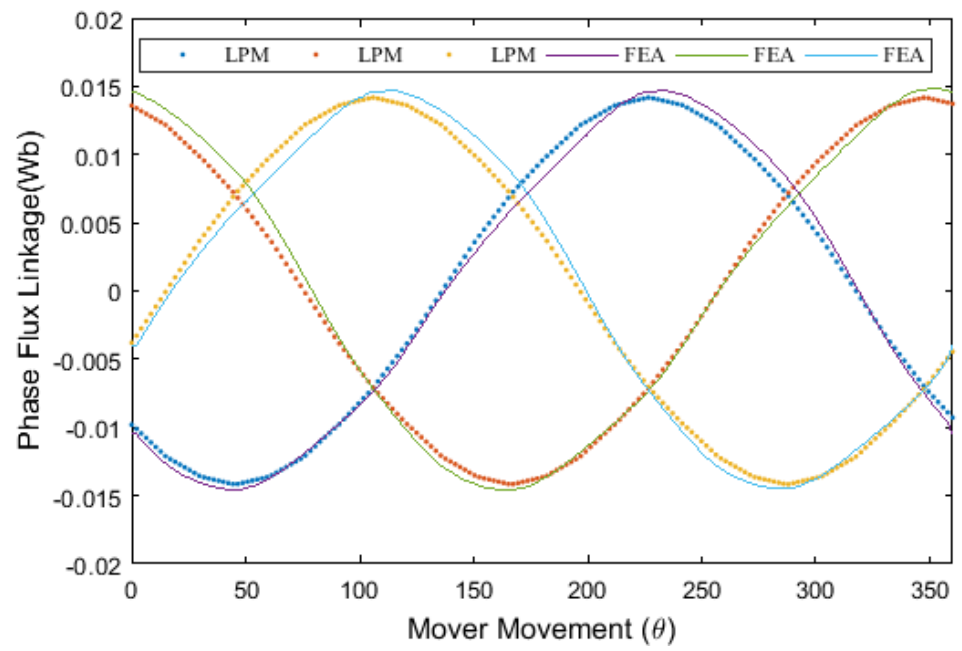

(b)

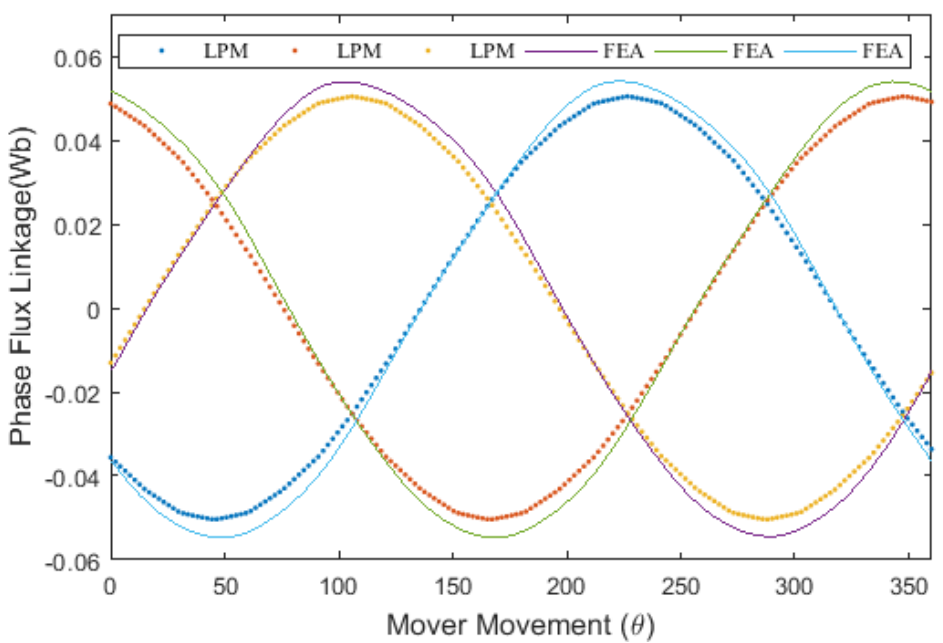

(c)

Figure 6. (a) PM flux linkage FEA vs. LPM (b) FE flux linkage FEA vs. LPM (c) PM+FE flux linkage FEA vs. LPM. 
Table 3. Computational time and drive storage comparison.

\begin{tabular}{ccc}
\hline Analysis Method & Time & Drive Storage \\
\hline LPM & $4.67 \mathrm{~s}$ & $126 \mathrm{KBs}$ \\
2D FEA & 7 min and $48 \mathrm{~s}$ & $217 \mathrm{MBs}$ \\
\hline
\end{tabular}

\section{Analysis of Single-Sided VFPMLM}

After evaluating the initial performance of the proposed machine through LPM, different performance parameters like three-phase no-load flux linkage (FE and PM both), Total Harmonic Distortion (THD) of middle phase and its corresponding harmonic frequency spectrum, detent force, average thrust force $\left(T F_{a v g}\right)$, and thrust force density (TFD) are analyzed. Parameters like no-load flux linkage, detent, and thrust force are taken directly from 2D FEA solver while to find THD, TFD and $T F_{\text {avg }}$ per PM volume, the following equations are utilized.

$$
\begin{gathered}
\text { THD }=\frac{\sqrt{\sum_{i=2}^{m} \Phi_{i}^{2}}}{\Phi_{1}} \\
T F D=\frac{T F_{a v g}}{V_{m}} \\
T F_{a v g} \text { per PM volume }=\frac{T F_{a v g}}{V_{P M}}
\end{gathered}
$$

$\Phi_{1}$ represents the flux linkage of fundamental component while $\Phi_{2}$ up to $\Phi_{m}$ represent the harmonic components. $V_{m}$ and $V_{P M}$ is the volume of mover and PM respectively.

\section{Multivariable Geometric Optimization}

Multivariable geometric optimization (MGO) is employed to investigate the influence of different design parameters on the improvement of the initial electromagnetic performance of the proposed single-sided VFPMLM. MGO is a sequential optimization technique and does not depends on the previous values of the variables. Firstly, a set of variables are defined that has a combined influence on the objective function, and their respective ranges are defined. MGO is started to ensure the achievement of the global maximum. If the set target is not achieved, then the set of variables are refined. During MGO implementation, electric and magnetic loadings, slot area, air gap length, and stack length are kept constant to ensure that it is only applied to design parameters and their configuration. The flow chart for MGO is shown in Figure 7. MGO is used to improve the key parameters like $T F_{a v g}$, thrust force ripples $\left(T F_{\text {rip }}\right)$ and $T F D$. For the implementation of MGO, the objective function, constraints, set of variables to be optimized, and their respective ranges are defined as:

$$
\begin{aligned}
& \text { ObjectiveFunction: } \max \left(T F_{a v g}, T F D\right) \text { and } \\
& \min \left(F_{d}, T F_{\text {rip }}, T H D\right) \\
& \text { Constraints: } T F_{\text {avg }} \geq 165.21 \mathrm{~N}, T F D \geq 322 \mathrm{kN} / \mathrm{m}^{3} \\
& F_{d} \leq 36.1 \mathrm{~N} \text { and } T F_{\text {rip }} \leq 60 \mathrm{~N}
\end{aligned}
$$




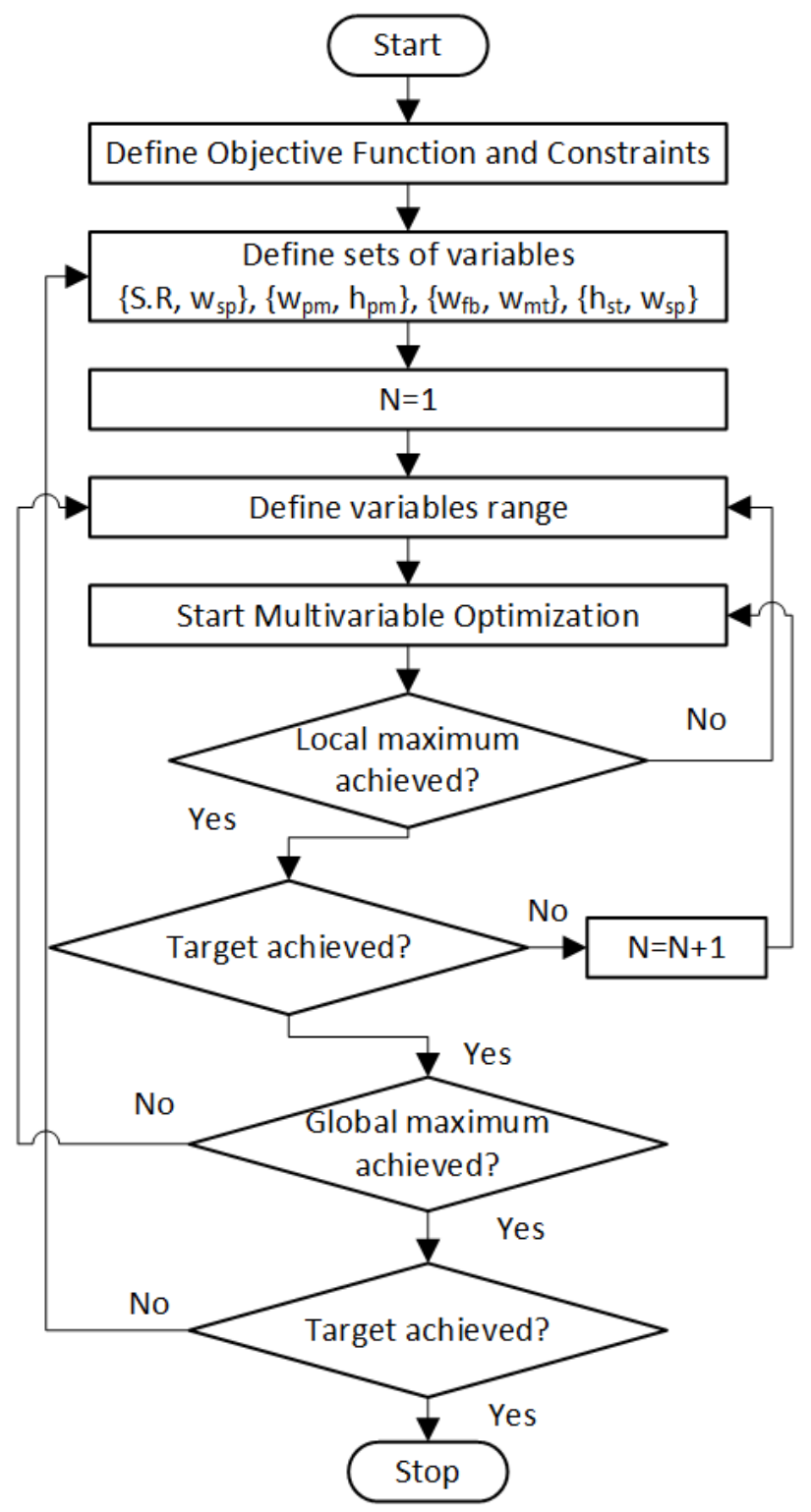

Figure 7. Flow chart for MGO.

\subsection{Influence of S.R and $w_{s p}$}

The split ratio defined by Equation (17) is the main parameter, its value is wisely chosen to avoid saturation of back iron, while the width of the stator pole has a great influence on no-load flux linkage. The value of these variables are varied in the specified range and the results are shown in Figure 8. From Figure 8 it is clear that at S.R $=0.1989$ and $w_{s p}=7.5 \mathrm{~mm}, T F_{\text {avg }}$ increased from $165.21 \mathrm{~N}$ to $179.08 \mathrm{~N}$, TFD is increased from $322 \mathrm{kN} / \mathrm{m}^{3}$ to $349.1 \mathrm{kN} / \mathrm{m}^{3}$. Ripples in the thrust force are reduced from $60 \mathrm{~N}$ to $57 \mathrm{~N}$. THD is decreased from $3.47 \%$ to $2.85 \%$.

$$
S . R=\frac{h_{s}+A_{g}}{h_{s}+A_{g}+h_{m}}
$$




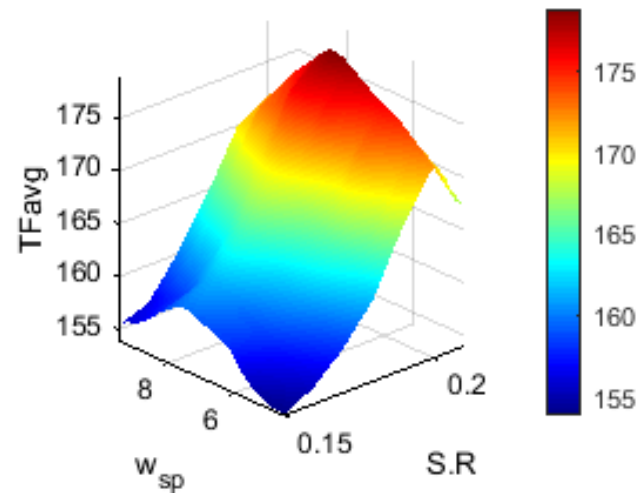

(a)

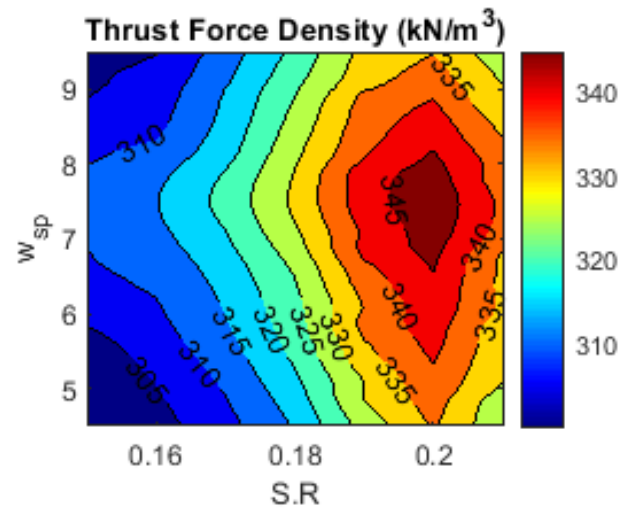

(b)

Figure 8. Influence of S.R and $w_{s p}$ on (a) $T F_{a v g}(\mathbf{b}) T F D$.

\subsection{Influence of $w_{p m}$ and $h_{p m}$}

Here the permanent magnet height and width are optimized in their specified ranges keeping the volume fixed, and their influence is observed in Figure 9. PM width variation is also dependent on mover tooth width so its value is carefully optimised. Analysis reveals that $w_{p m}$ and $h_{p m}$ of the PM improves TF $F_{a v g}$ from $179.08 \mathrm{~N}$ to $184.95 \mathrm{~N}, T F D$ is increased from $349.1 \mathrm{kN} / \mathrm{m}^{3}$ to $360.5 \mathrm{kN} / \mathrm{m}^{3} . T F_{\text {rip }}$ are decreased from $57 \mathrm{~N}$ to $55 \mathrm{~N}$. Initially, the $w_{p m}$ was $4 \mathrm{~mm}$ and $h_{p m}$ was $24 \mathrm{~mm}$ are optimized to $w_{p m}=4.05 \mathrm{~mm}$ and $h_{p m}=23.7 \mathrm{~mm}$. THD is reduced from $2.85 \%$ to $2.22 \%$.

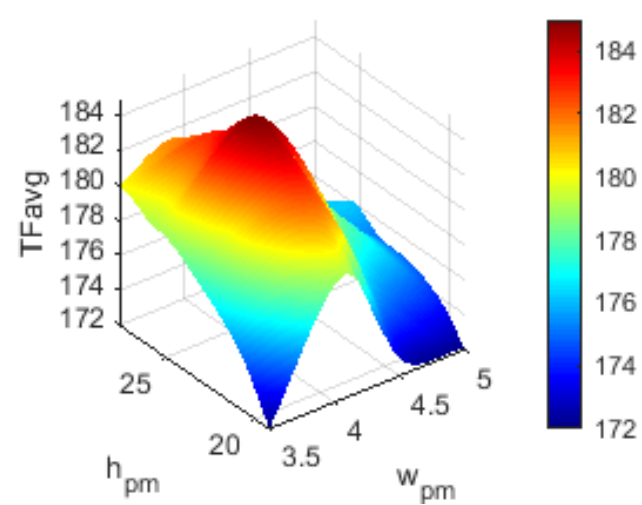

(a)

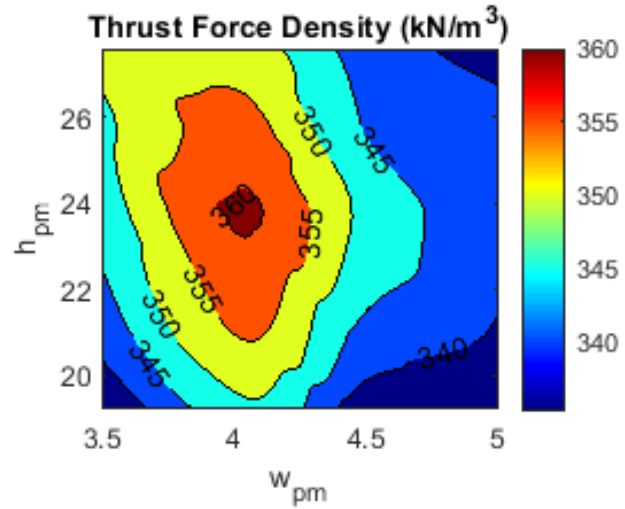

(b)

Figure 9. Influence of $w_{p m}$ and $h_{p m}$ on (a) $T F_{a v g}$ (b) TFD.

\subsection{Influence of $w_{m t}$ and $w_{f b}$}

Single-sided VFPMLM is designed such that the flux bridge eliminates the flux leakage via mover, so the magnetic flux passes through the mover core and converts the leakage into a flux linkage. The width of the flux bridge was initially set to $1 \mathrm{~mm}$ but the improvement was observed in thrust force by minimizing its width. So its value is optimized along with the width of the mover's tooth $\left(w_{m t}\right)$. The optimised $w_{f b}$ is kept at $0.8 \mathrm{~mm}$. Initially the $w_{m t}$ was taken $4 \mathrm{~mm}$ which is optimized to $4.85 \mathrm{~mm}, T F_{\text {avg }}$ increased from $184.95 \mathrm{~N}$ to $208.12 \mathrm{~N}$, TFD is increased from $360.5 \mathrm{kN} / \mathrm{m}^{3}$ to $405.68 \mathrm{kN} / \mathrm{m}^{3}$. TF rip are decreased from $55 \mathrm{~N}$ to $51.5 \mathrm{~N}$. Figure 10 shows the detailed analyses. THD is reduced from $2.22 \%$ to $1.89 \%$. 


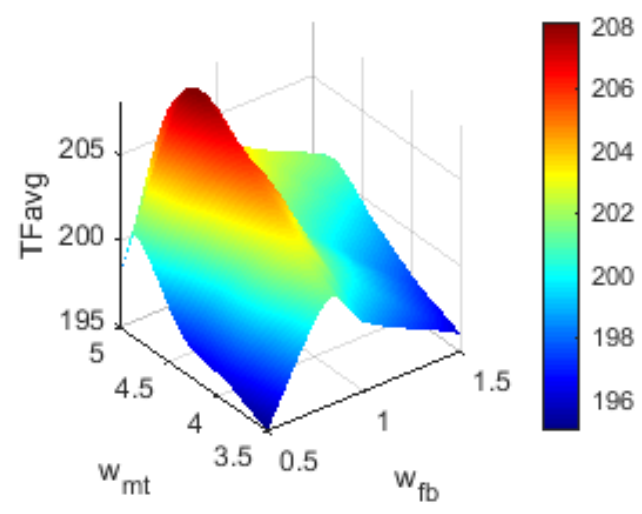

(a)

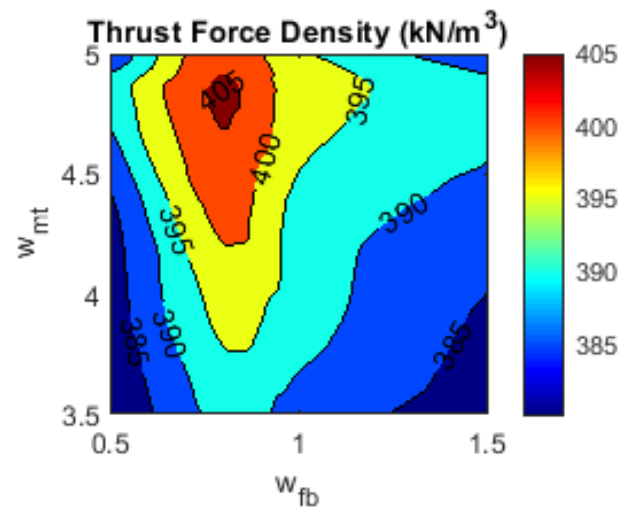

(b)

Figure 10. Influence of $w_{f b}$ and $w_{m t}$ on (a) $T F_{a v g}(\mathbf{b}) T F D$.

\subsection{Influence of $h_{s t}$ and $w_{s p}$}

The depth of stator slot $\left(h_{s t}\right)$ is optimized along stator pole width $\left(w_{s p}\right)$ and its effect on the performance is shown in Figure 11 . Initially $h_{s t}$ was taken $4.5 \mathrm{~mm}$ which is optimized to $5 \mathrm{~mm}$, and $w_{s p}$ is once again optimized with $h_{s t}$, so the revised optimized value of $w_{s p}$ is $5.2 \mathrm{~mm}$ that improves $T F_{a v g}$ from $208.12 \mathrm{~N}$ to $223.04 \mathrm{~N}, T F D$ is increased from $405.68 \mathrm{kN} / \mathrm{m}^{3}$ to $434.76 \mathrm{kN} / \mathrm{m}^{3}$. TF $F_{\text {rip }}$ and $T H D$ are decreased from $51.5 \mathrm{~N}$ to $46 \mathrm{~N}$ and from $1.89 \%$ to $1.27 \%$ respectively.

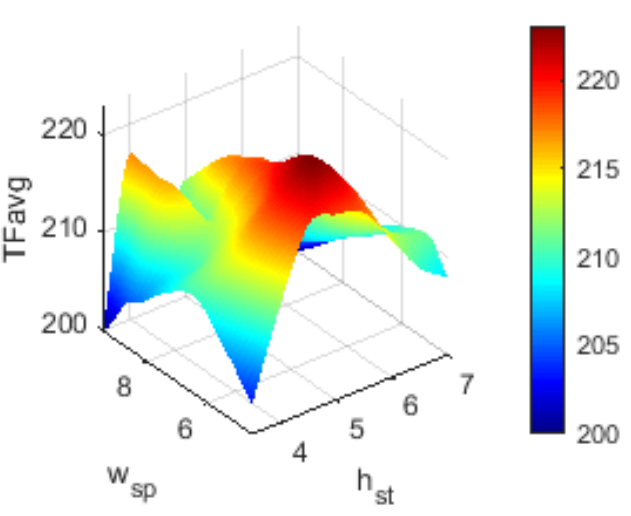

(a)

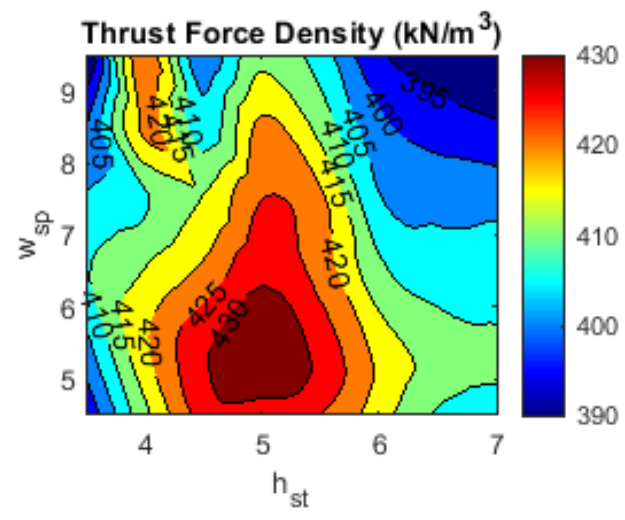

(b)

Figure 11. Influence of $h_{s t}$ and $w_{s p}$ on (a) $T F_{a v g}(\mathbf{b}) T F D$.

After all optimization stages are completed, Table 4 is obtained which compares the performance of initial and optimized design.

Table 4. Performance based comparison of initial design and optimized design.

\begin{tabular}{cccc}
\hline Parameter & Initial Values & Optimized Values & Improvements \\
\hline Flux Linkage $(\mathrm{Wb})$ & 0.12112 & 0.17455 & $44.11 \%$ \\
THD $(\%)$ & 3.47 & 1.27 & $63.40 \%$ \\
Detent Force $(\mathrm{N})$ & 36.05 & 4.51 & $87.49 \%$ \\
$T F_{\text {avg }}(\mathrm{N})$ & 165.21 & 223.04 & $35.0 \%$ \\
TFD $\left(\mathrm{kN} / \mathrm{m}^{3}\right)$ & 322 & 434.76 & $35.02 \%$ \\
$T F_{\text {rip }}(\mathrm{N})$ & 60 & 46 & $23.33 \%$ \\
\hline
\end{tabular}




\section{FEA Based Performance Analysis}

\subsection{Flux Strength and Flux Regulation}

When the machine is in the initial position, the flux line distribution of the optimized design is shown in Figure 12. Figure 13a shows the no-load flux linkage of the initial design and optimized design, while the corresponding harmonics are shown in Figure 13b,c respectively. Figure 14a shows the influence of field excitation on the flux linkage. Phase A is the middle phase and is not affected by the end effect, which is the problem in linear machines. Figure $14 \mathrm{~b}$ shows the flux weakening and enhancing capability of the proposed machine under various FE current densities i.e., $J_{e}=0, \pm 4, \pm 8, \pm 12\left(\mathrm{~A} / \mathrm{mm}^{2}\right)$. When the current density is positive, the flux density in the air gap increases which results in an enhanced flux linkage whereas when the current density is negative, the flux density in the air gap is reduced causing a decrease in the flux linkage. To conclude, the flux regulation capability of the proposed single-sided VFPMLM mainly depends upon the FE current and the flux linkage is symmetrical and sinusoidal.

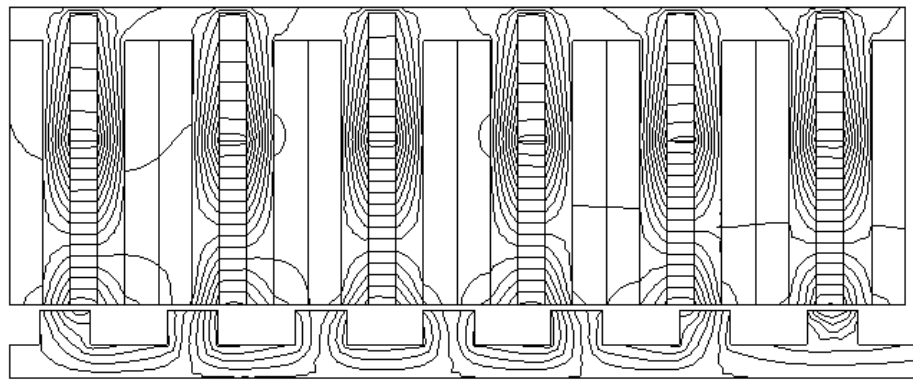

Figure 12. Flux line distribution of proposed design at initial position.

\subsection{Detent Force and Average Thrust Force}

Detent force is also one of the main factors in evaluating the performance of the machine to analyze the noise and vibration. It arises at no load due to the attractive force between the secondary core and the mover PM. The stronger force of attraction leads to higher vibration and noise and, hence, lower output $T F_{\text {avg. }}$. Figure 15 depicts the detent force of the initial and optimized design. The average thrust force of the proposed singlesided VFPMLM is improved after optimization as shown in Figure 16. Compared with the initial design, the optimized model has an average thrust increase of $35 \%$, which is an increase of $45.35 \%$ compared with the HEFSM proposed in literature [18] with the same stack length and area of the two machine movers. In the initial design, the $T F_{a v g}$ was $165.21 \mathrm{~N}$, which is increased to $223.04 \mathrm{~N}$ after optimization under the same electric and magnetic loading. In the Figure 17, the armature current density $\left(J_{A C}\right)$ is varied from 0 to $18 \mathrm{~A} / \mathrm{mm}^{2}$ and the variation in $T F_{a v g}$ is observed. The $T F_{\text {avg g grows linearly }}$ when the current density increases up to $14 \mathrm{~A} / \mathrm{mm}^{2}$, as can be observed. The thrust force grows slowly when the current density surpasses $14 \mathrm{~A} / \mathrm{mm}^{2}$ due to saturation of the iron components. 


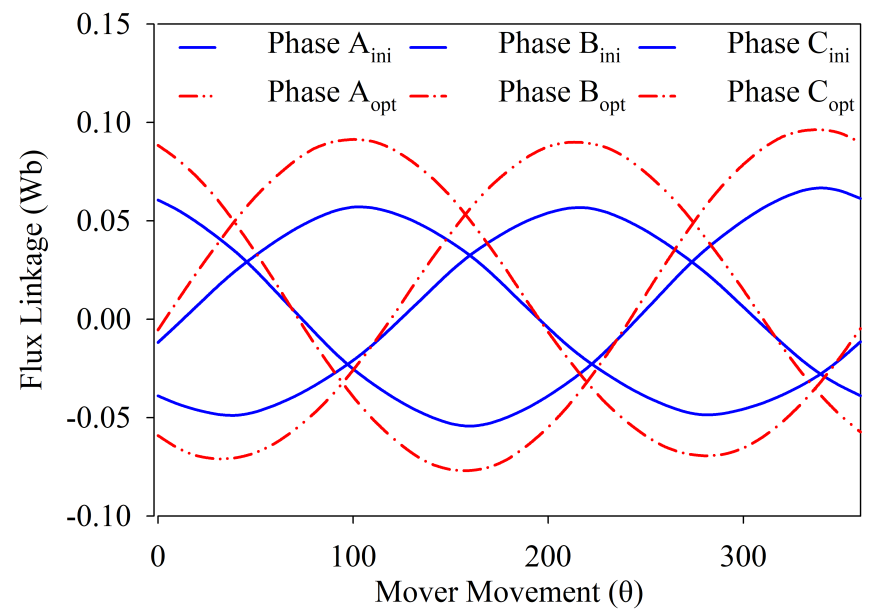

(a)

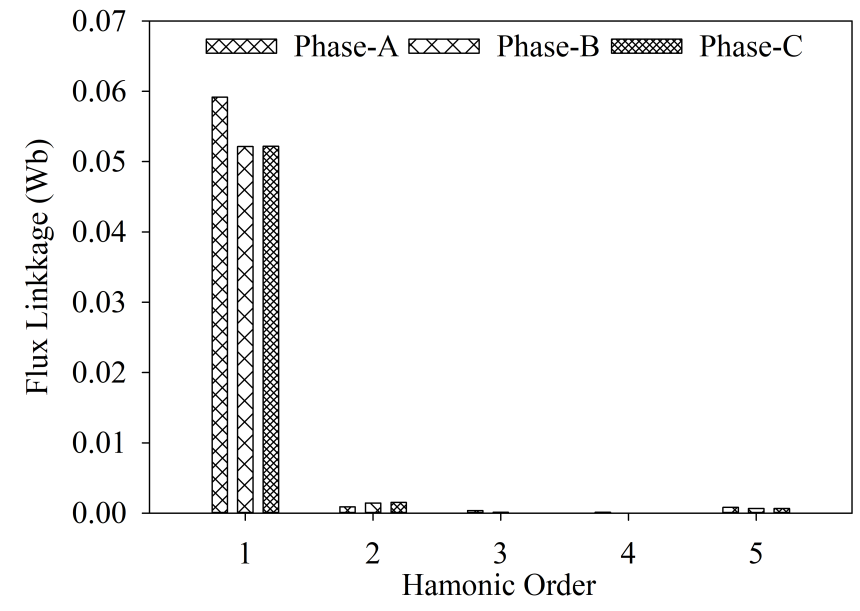

(b)

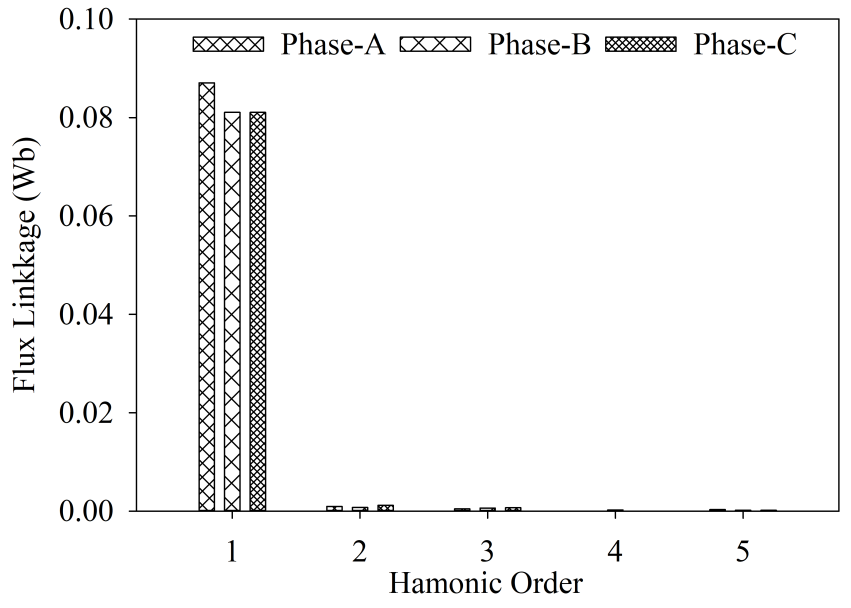

(c)

Figure 13. (a) Flux linkage of the proposed single-sided VFPMLM (b) Harmonics in initial design's flux linkage (c) Harmonics in optimized design's flux linkage.

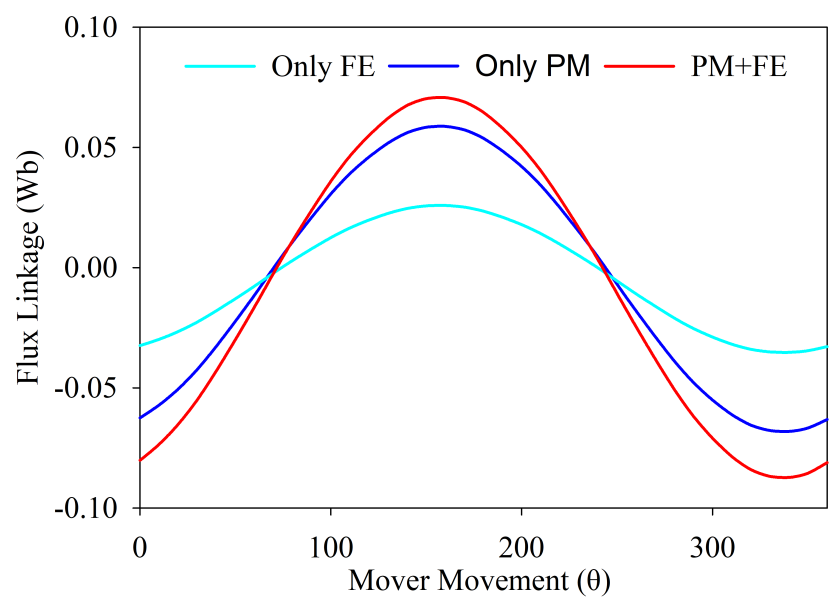

(a)

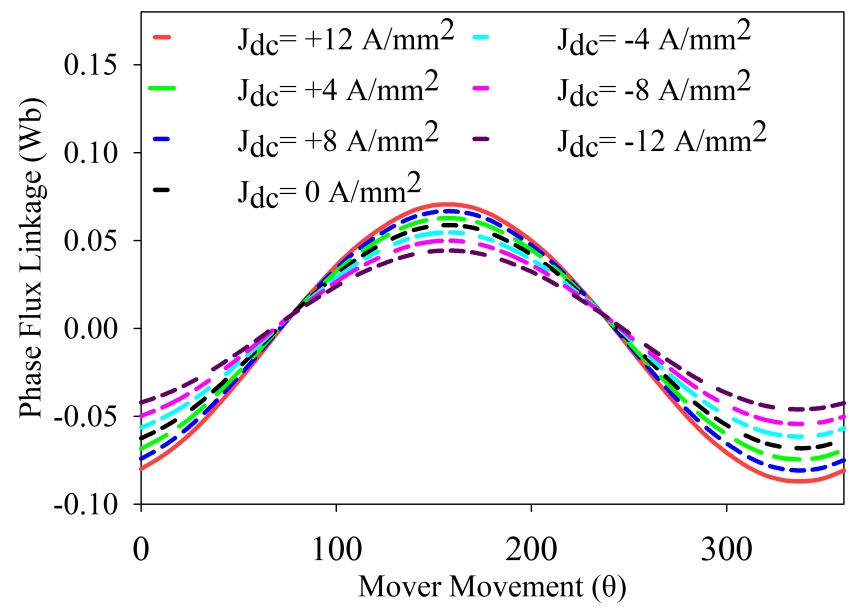

(b)

Figure 14. (a) Influence of FE on flux linkage (b) Flux regulation capability of the proposed single-sided VFPMLM with field current density. 


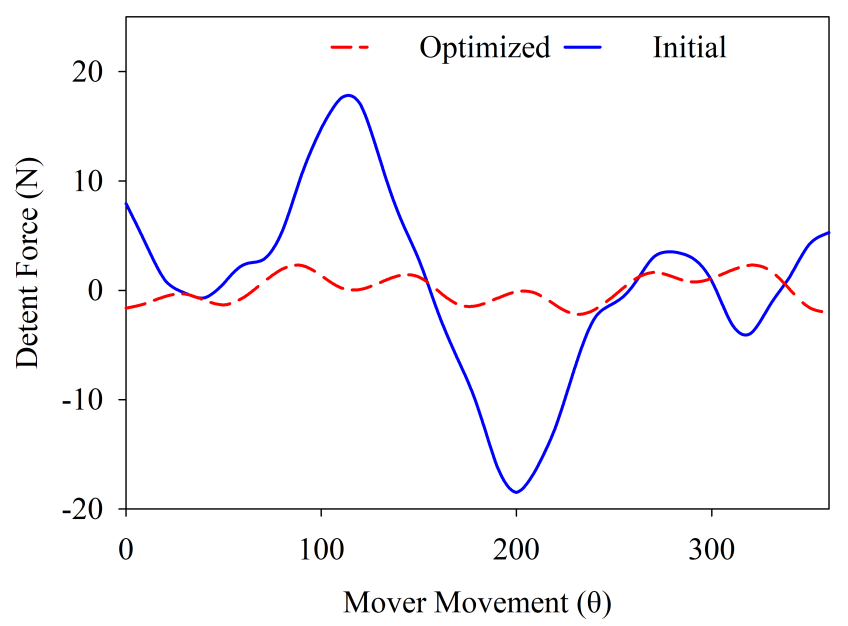

Figure 15. Detent force of the proposed single-sided VFPMLM.

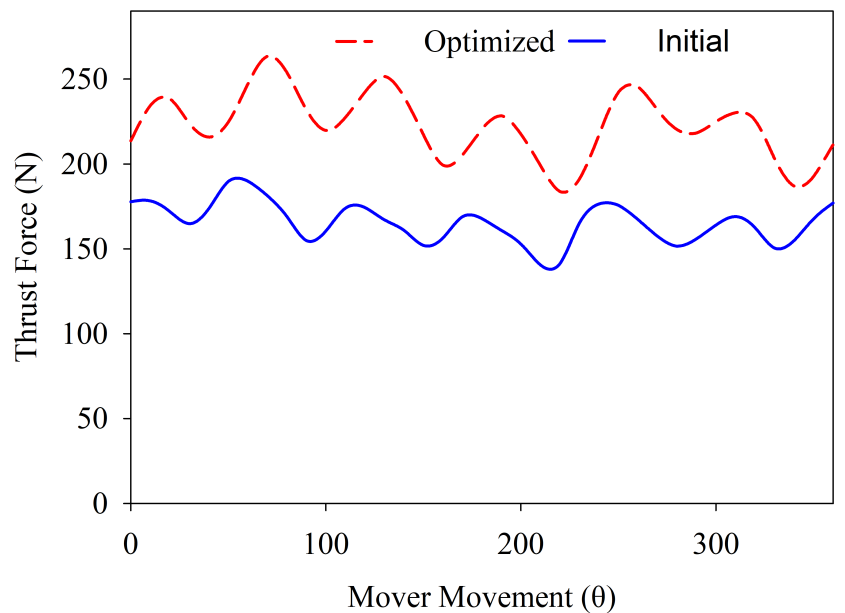

Figure 16. Thrust force of the proposed single-sided VFPMLM.

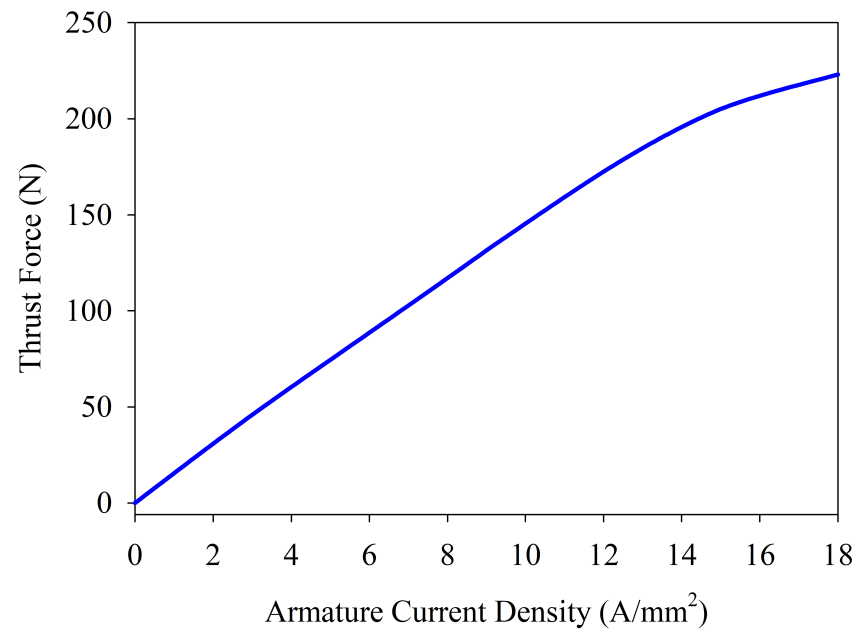

Figure 17. Variation of $T F_{a v g}$ with $J_{A C}$.

\subsection{D Analysis}

$3 \mathrm{D}$ analysis of the proposed design is done to verify the results obtained by 2D analysis. Figure 18 compares the flux linkage of 2D and 3D designs. The flux linkage of 3D design shows a small decrement as compared to 2D design due to the end effects. Figure 19 shows 
the detent force and thrust force is depicted in Figure 20. Due to the longitudinal end effect, the thrust force of $3 \mathrm{D}$ is less in magnitude and has more ripples as compared to $2 \mathrm{D}$ design.

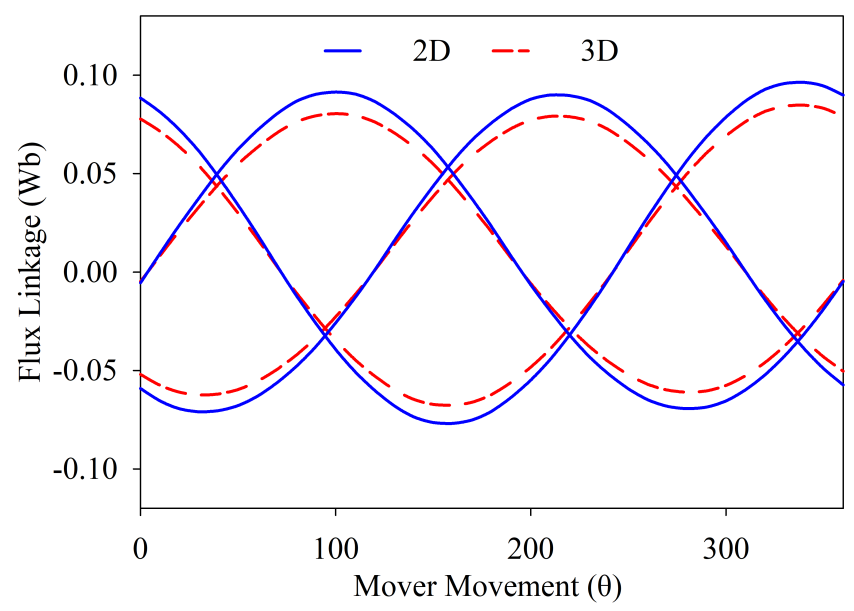

Figure 18. Flux linkage of 3D and 2D single-sided VFPMLM.

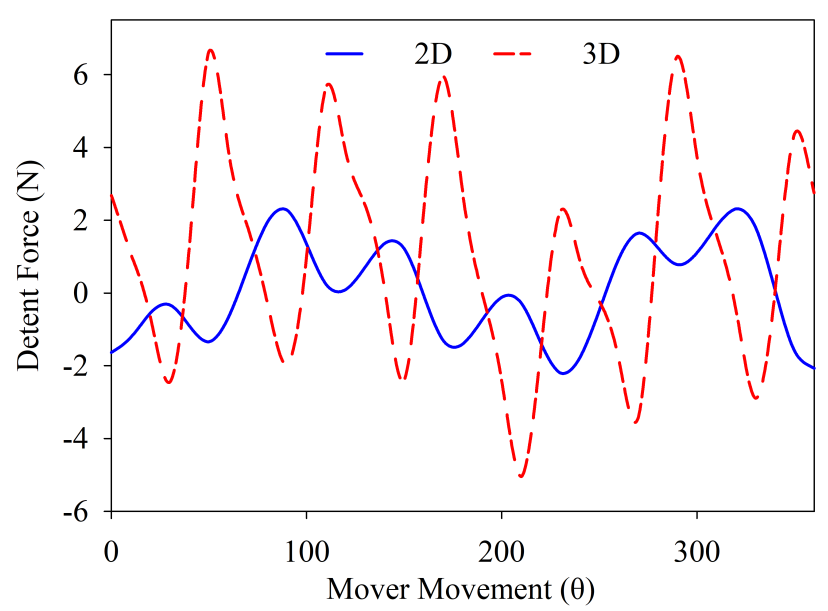

Figure 19. Detent force of 3D and 2D single-sided VFPMLM.

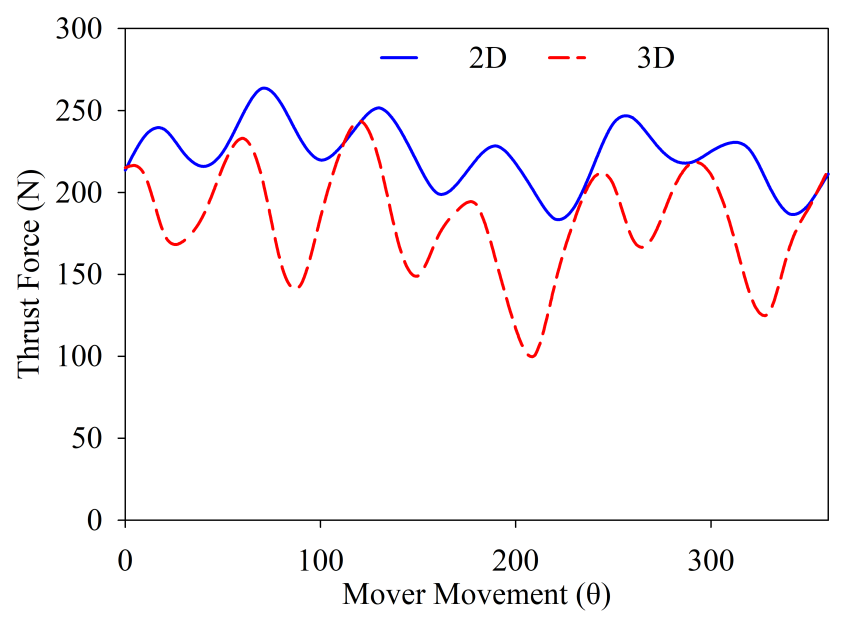

Figure 20. Thrust force of 3D and 2D single-sided VFPMLM.

\subsection{Force-Velocity and Power-Velocity Characteristic Curve}

Using the approach presented in [30,31], force-velocity and power-velocity curves are calculated for the proposed machine. The force-velocity curve is shown in Figures 21 and 22 
shows the power velocity curve. The analysis reveals that the proposed single-sided VFPMLM achieved a maximum thrust force of $223.04 \mathrm{~N}$ at the velocity of $6.26 \mathrm{~m} / \mathrm{s}$ while the power reaches $1393 \mathrm{~W}$. Since force has an inverse relation with velocity, so at higher speeds, thrust force decreases maintaining a constant output power. It can be seen from Figure 22 that the proposed single-sided VFPMLM shows a better constant power operation capability.

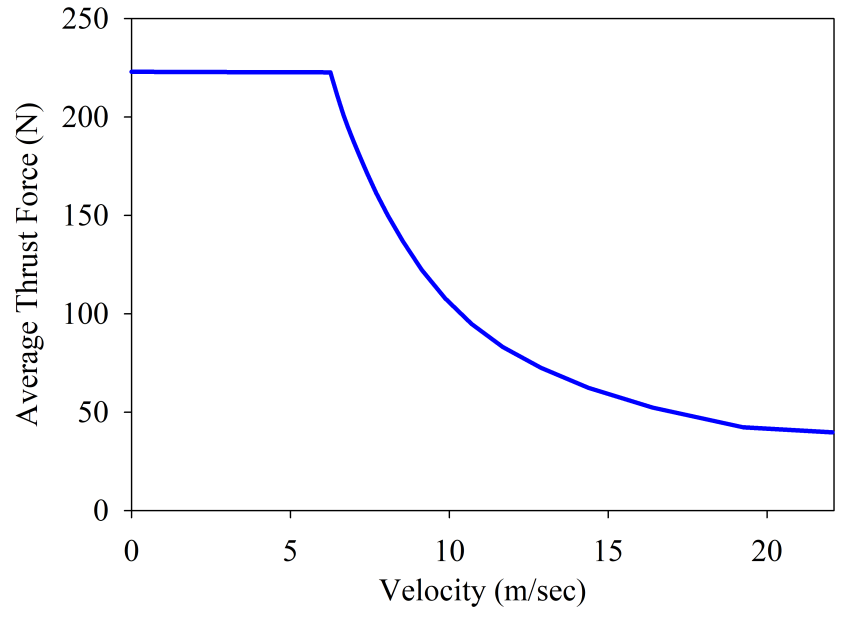

Figure 21. Average thrust force at different velocities.

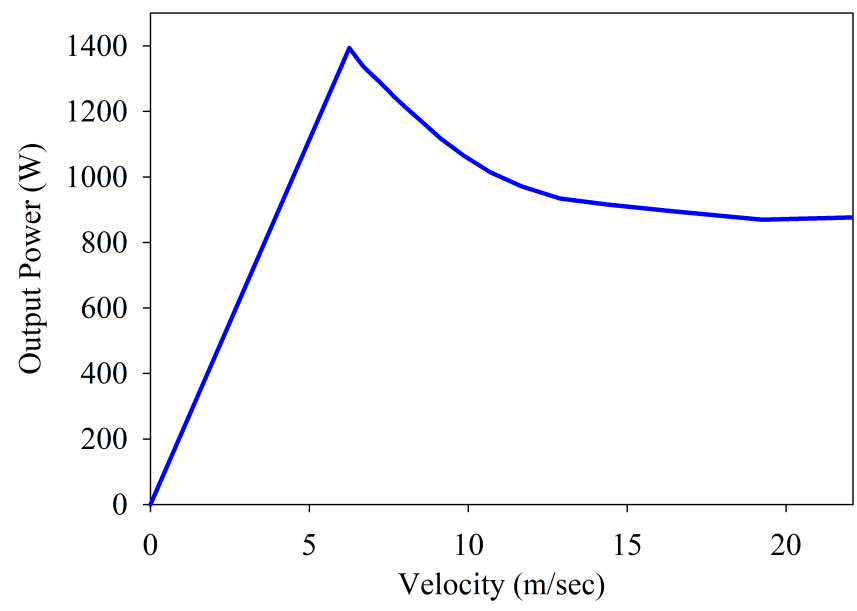

Figure 22. Output power at different velocities.

\subsection{Efficiency Analysis}

The output power in linear machines is the product of $T F_{\text {avg }}$ and corresponding velocity while input power is calculated by the combination of output power and total losses (iron and copper losses). The losses are calculated at different points with the variable velocity and electric loading under the force-velocity graph. The points taken are comprised of current and current control angles shown in Figure 23. The copper losses can be calculated using Equation (20) while iron losses are calculated from 2D FEA using JMAG at all the selected points. For the efficiency calculation at each point, FE simulations are executed while iron and copper losses are considered. At point 1 , the copper and iron losses of $150 \mathrm{~W}$ and $212 \mathrm{~W}$ are noted while at point 3 , the iron losses were at a maximum (approximately $260 \mathrm{~W}$ ), and hence efficiency is lower. The average efficiency of the proposed machine at different points is $72 \%$ as shown in Figure 24.

$$
P_{c u}=P_{c u}(A E)+P_{c u}(F E)
$$


Also from [32],

$$
P_{c u}=I \rho J L(N Q)(1000)
$$

(18) becomes

$$
P_{c u}=2 \operatorname{I} \rho J L(N Q)(1000)
$$

where $I, \rho, J, L, N, Q$ represents current (in rms if armature), resistivity $(\Omega-m)$, current density $\left(\mathrm{A} / \mathrm{mm}^{2}\right)$, length of wire $(\mathrm{mm})$, number of turns and number of slot pairs respectively.

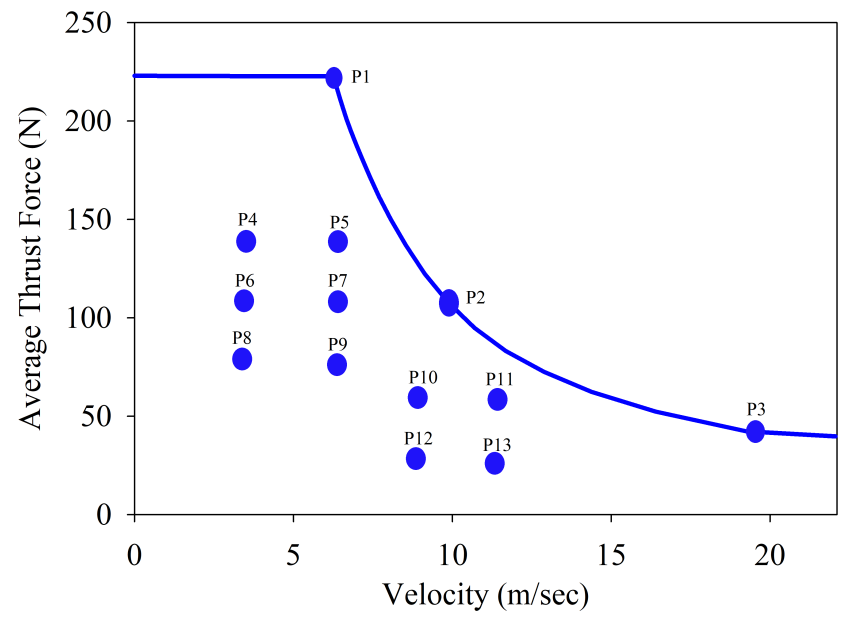

Figure 23. Points at which efficiency is calculated.

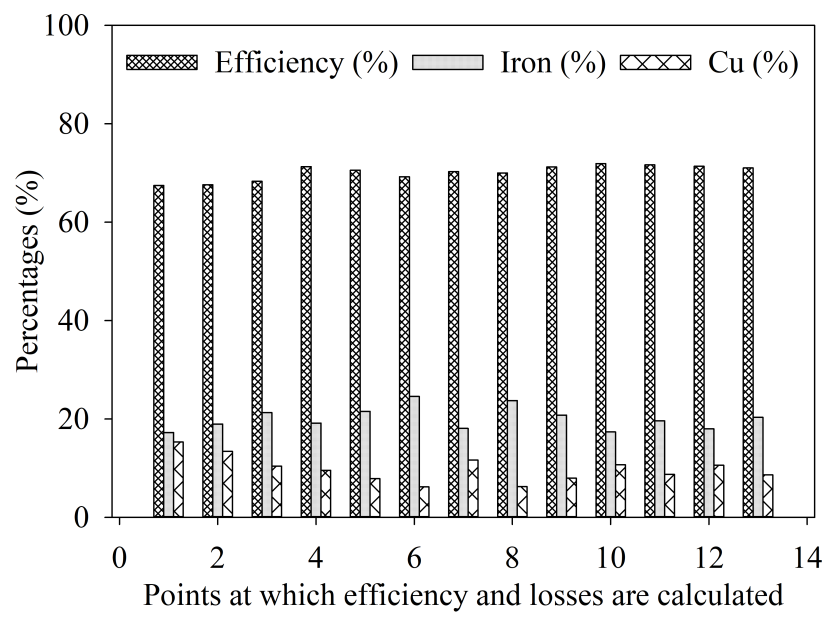

Figure 24. Efficiency at different points taken on Force-Velocity curve.

\subsection{Thermal Analysis}

In the electrical machine design process, thermal analysis plays an important role in setting operating limits and selecting insulating classes. The long-time operation of singlesided VFPMLM is limited by heat dissipation. If the temperature surpasses a particular allowable range, it will cause the electromagnetic performance to decrease and leads to inter turns short circuit fault [33]. The flow of current through the conductor causes heat dissipation and loss of power. This generation of heat in the winding will increase the heat of the entire machine. Apart from the copper losses associated with the windings, the machine also posses core losses. The core loss is the eddy current loss and hysteresis loss that occurs in the core of the machine. All these losses act as heat sources and cause a temperature rise. Therefore, the losses can be determined through the magnetic loss study, and thermal analysis can be performed to analyze the temperature distribution.

Firstly, losses are calculated in 3D FEA analysis of the proposed machine and then thermal analysis in 3D thermal studies is performed, as 3D analysis has more accuracy 
as compared to the $2 \mathrm{D}$ analysis. To acquire the temperature distribution of the complete machine, the 3D loss study is combined with the 3D heat study. The 3D thermal study reveals that because of the presence of all sources of excitation on the mover, the mover temperature rises very sharply, while the temperature of the secondary rises slightly, as the secondary of the proposed machine is made of iron only and is completely robust. The contour plot of the temperature distribution is shown in Figure 25. The temperature distribution in the mover attains a maximum value of $54.44{ }^{\circ} \mathrm{C}$ noticed in the windings. The maximum temperature at the secondary poles is $52.98{ }^{\circ} \mathrm{C}$. Even at high temperatures, the proposed machine shows better thrust force. The temperature of the proposed machine can be lowered by using several cooling methods.

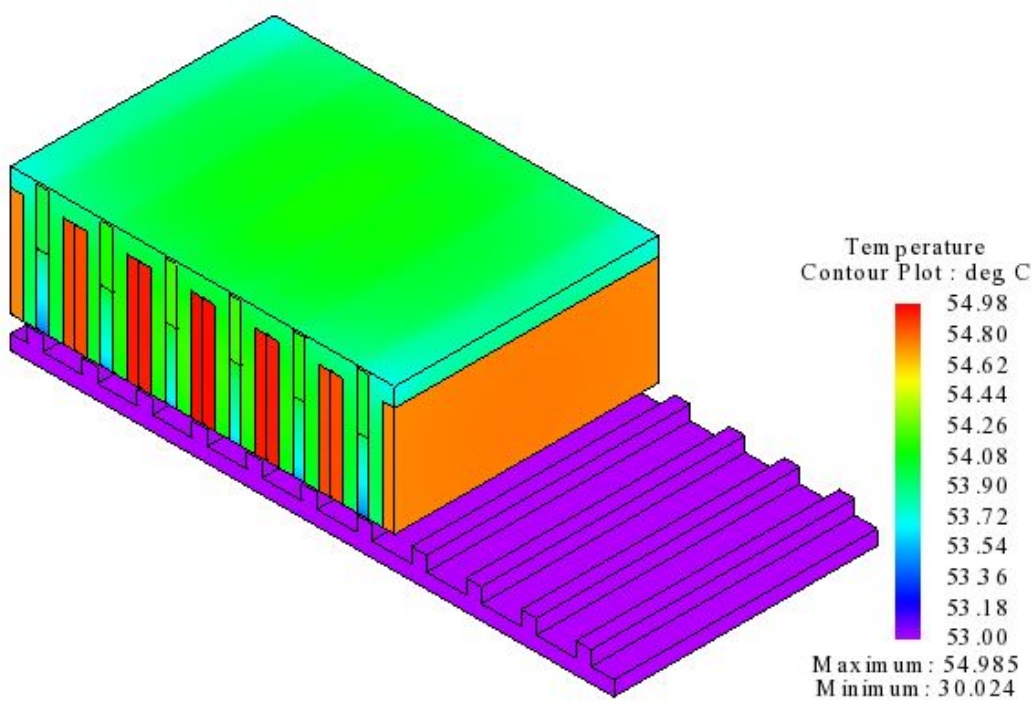

Figure 25. 3D thermal analysis of the proposed machine.

\subsection{Comparison with Conventional Model}

Finally, the single-sided VFPMLM presented is compared to the conventional design [18]. A detailed comparison is drawn in Table 5. The proposed design offers high average thrust force, high thrust force density, and high average thrust force per PM volume with the reduced number of armature excitation turns, field excitation turns while keeping the volume of PM the same as conventional design. Further, the proposed design offers constant power operation at high speeds.

Table 5. Detailed comparison of the proposed and conventional design.

\begin{tabular}{|c|c|c|}
\hline Parameter & Proposed & Conventional \\
\hline Mover length & $131 \mathrm{~mm}$ & $131 \mathrm{~mm}$ \\
\hline Machine total height & $54.3 \mathrm{~mm}$ & $54.3 \mathrm{~mm}$ \\
\hline Stack Length & & \\
\hline Air gap & & \\
\hline No. of armature slots & & \\
\hline No. of DC slots & 3 & 7 \\
\hline Field Current & & \\
\hline Armature Turns & 226 & 276 \\
\hline DC Turns & 51 & 81 \\
\hline Thrust Force & $223.04 \mathrm{~N}$ & $153.45 \mathrm{~N}$ \\
\hline$T F_{a v g}$ per PM Volume & $4.302 \mathrm{~N} / \mathrm{cm}^{3}$ & $2.77 \mathrm{~N} / \mathrm{cm}^{3}$ \\
\hline TFD & $434.76 \mathrm{kN} / \mathrm{m}^{3}$ & $265.325 \mathrm{kN} / \mathrm{m}^{3}$ \\
\hline
\end{tabular}




\section{Conclusions}

This work proposed and investigated a single-sided VFPMLM which combines the advantages of permanent magnet machines (high thrust density) and wound field machines (flux adjustment capability). The flux bridge prevents the leakage flux from the mover and converts it into flux linkage, which greatly influences the performance of the machine. LPM is used to evaluate initial performance, which greatly reduces the computational time and drive storage. The proposed machine replaces the expensive rare earth PMs with ferrite magnets and improves flux controlling capability at various excitation currents. MGO is utilized to optimize the leading design parameters. The optimized design has improved flux linkage up to $44.11 \%, T F_{a v g}$ up to $35 \%$, TFD up to $35.02 \%$, reduced thrust force ripples $\left(T F_{\text {rip }}\right)$ by $23 \%$ and detent force $\left(F_{d}\right)$ by $87.5 \%$. The results obtained by $2 \mathrm{D}$ analysis are verified by $3 \mathrm{D}$ analysis. Finally, thermal analysis in $3 \mathrm{D}$ is done to set the operating limit and to select a proper insulating class for the proposed machine. Overall, the presented single-sided VFPMLM outperforms the conventional HEFSM that has been previously proposed in the literature.

Author Contributions: Conceptualization, B.U. and F.K.; methodology, B.U.; software, B.U., M.Q.; validation, B.U., B.K. and Z.D.; formal analysis, A.H.M., K.M.C.; investigation, A.H.M., Z.D.; resources, F.K., K.M.C.; data curation, Z.D.; original draft preparation, B.U.; review and editing, F.K.; supervision, F.K.; project administration, F.K., A.H. Milyani, K.M.C.; funding acquisition, A.H.M., K.M.C. All authors have read and agreed to the published version of the manuscript.

Funding: There is no external funding.

Acknowledgments: This work was supported by COMSATS University Islamabad, Abbottabad Campus and Higher Education Commission of Pakistan (No. TDF-03-067/R\&D/HEC/2019).

Conflicts of Interest: The authors declare no conflict of interest.

\section{References}

1. Jin, M.J.; Wang, C.F.; Shen, J.X.; Xia, B. A modular permanent-magnet flux-switching linear machine with fault-tolerant capability. IEEE Trans. Magn. 2009, 45, 3179-3186. [CrossRef]

2. Huang, L.; Yu, H.; Hu, M.; Liu, H. Study on a long primary flux-switching permanent magnet linear motor for electromagnetic launch systems. IEEE Trans. Plasma Sci. 2013, 41, 1138-1144. [CrossRef]

3. Zhou, G.; Huang, X.; Jiang, H.; Tan, L.; Dong, J. Analysis method to a Halbach PM ironless linear motor with trapezoid windings. IEEE Trans. Magn. 2011, 47, 4167-4170. [CrossRef]

4. Mirzaei, M.; Abdollahi, S.E.; Lesani, H. A large linear interior permanent magnet motor for electromagnetic launcher. IEEE Trans. Plasma Sci. 2011, 39, 1566-1570. [CrossRef]

5. Zhu, Z.; Chen, J.; Pang, Y.; Howe, D.; Iwasaki, S.; Deodhar, R. Analysis of a novel multi-tooth flux-switching PM brushless AC machine for high torque direct-drive applications. IEEE Trans. Magn. 2008, 44, 4313-4316. [CrossRef]

6. Hellinger, R.; Mnich, P. Linear motor-powered transportation: History, present status, and future outlook. Proc. IEEE 2009, 97, 1892-1900. [CrossRef]

7. Cao, R.; Lu, M.; Jiang, N.; Cheng, M. Comparison between linear induction motor and linear flux-switching permanent-magnet motor for railway transportation. IEEE Trans. Ind. Electron. 2019, 66, 9394-9405. [CrossRef]

8. Azer, P.; Bilgin, B.; Emadi, A. Mutually Coupled Switched Reluctance Motor: Fundamentals, Control, Modeling, State of the Art Review and Future Trends. IEEE Access 2019, 7, 100099-100112. [CrossRef]

9. Wang, H.; Li, J.; Qu, R.; Lai, J.; Huang, H.; Liu, H. Study on high efficiency permanent magnet linear synchronous motor for maglev. IEEE Trans. Appl. Supercond. 2018, 28, 1-5. [CrossRef]

10. Zhao, W.; Cheng, M.; Ji, J.; Cao, R.; Du, Y.; Li, F. Design and analysis of a new fault-tolerant linear permanent-magnet motor for maglev transportation applications. IEEE Trans. Appl. Supercond. 2012, 22, 5200204. [CrossRef]

11. Cao, R.; Cheng, M.; Mi, C.; Hua, W.; Wang, X.; Zhao, W. Modeling of a complementary and modular linear flux-switching permanent magnet motor for urban rail transit applications. IEEE Trans. Energy Convers. 2012, 27, 489-497. [CrossRef]

12. Cao, R.; Cheng, M.; Hua, W. Investigation and general design principle of a new series of complementary and modular linear FSPM motors. IEEE Trans. Ind. Electron. 2012, 60, 5436-5446. [CrossRef]

13. Zhou, Y.; Zhu, Z. Comparison of wound-field switched-flux machines. IEEE Trans. Ind. Appl. 2014, 50, 3314-3324. [CrossRef]

14. Abdollahi, S.E.; Vaez-Zadeh, S. Back EMF analysis of a novel linear flux switching motor with segmented secondary. IEEE Trans. Magn. 2013, 50, 1-9. [CrossRef] 
15. Ullah, N.; Basit, A.; Khan, F.; Shah, Y.A.; Khan, A.; Waheed, O.; Usman, A. Design and Optimization of Complementary Field Excited Linear Flux Switching Machine With Unequal Primary Tooth Width and Segmented Secondary. IEEE Access 2019, 7, 106359-106371. [CrossRef]

16. Liu, C.T.; Hwang, C.C.; Li, P.L.; Hung, S.S.; Wendling, P. Design optimization of a double-sided hybrid excited linear flux switching PM motor with low force ripple. IEEE Trans. Magn. 2014, 50. [CrossRef]

17. Gandhi, A.; Parsa, L. Hybrid flux-switching linear machine with fault-tolerant capability. In Proceedings of the 2015 IEEE International Electric Machines \& Drives Conference (IEMDC), Coeur d'Alene, ID, USA, 10-13 May 2015; pp. 715-720.

18. Hwang, C.C.; Li, P.L.; Liu, C.T. Design and analysis of a novel hybrid excited linear flux switching permanent magnet motor. IEEE Trans. Magn. 2012, 48, 2969-2972. [CrossRef]

19. Xu, L.; Zhao, W.; Ji, J.; Liu, G.; Du, Y.; Fang, Z.; Mo, L. Design and analysis of a new linear hybrid excited flux reversal motor with inset permanent magnets. IEEE Trans. Magn. 2014, 50. [CrossRef]

20. Zeng, Z.; Lu, Q.; Ye, Y. Optimization design of E-core hybrid-excitation linear switched-flux permanent magnet machine. Int. J. Appl. Electromagn. Mech. 2017, 54, 351-366. [CrossRef]

21. Sulaiman, E.; Kosaka, T.; Matsui, N. Design and performance of 6-slot 5-pole PMFSM with hybrid excitation for hybrid electric vehicle applications. In Proceedings of the 2010 International Power Electronics Conference-ECCE ASIA, Sapporo, Japan, 21-24 June 2010; pp. 1962-1968.

22. Gaussens, B.; Hoang, E.; Lécrivain, M.; Manfe, P.; Gabsi, M. A hybrid-excited flux-switching machine for high-speed DC-alternator applications. IEEE Trans. Ind. Electron. 2013, 61, 2976-2989. [CrossRef]

23. Hua, W.; Zhang, G.; Cheng, M. Flux-regulation theories and principles of hybrid-excited flux-switching machines. IEEE Trans. Ind. Electron. 2015, 62, 5359-5369. [CrossRef]

24. Hua, H.; Zhu, Z. Novel partitioned stator hybrid excited switched flux machines. IEEE Trans. Energy Convers. 2017, 32, 495-504 [CrossRef]

25. Zhang, L.; Fan, Y.; Lorenz, R.D.; Cui, R.; Li, C.; Cheng, M. Design and analysis of a new five-phase brushless hybrid-excitation fault-tolerant motor for electric vehicles. IEEE Trans. Ind. Appl. 2017, 53, 3428-3437. [CrossRef]

26. Gao, Y.; Li, D.; Qu, R.; Fan, X.; Li, J.; Ding, H. A novel hybrid excitation flux reversal machine for electric vehicle propulsion. IEEE Trans. Veh. Technol. 2017, 67, 171-182. [CrossRef]

27. Zhu, Z.; Pang, Y.; Howe, D.; Iwasaki, S.; Deodhar, R.; Pride, A. Analysis of electromagnetic performance of flux-switching permanent-magnet machines by nonlinear adaptive lumped parameter magnetic circuit model. IEEE Trans. Magn. 2005, 41, 4277-4287. [CrossRef]

28. Ullah, W.; Khan, F.; Umair, M. Lumped parameter magnetic equivalent circuit model for design of segmented PM consequent pole flux switching machine. Eng. Comput. 2020, 38, 572-585. [CrossRef]

29. Chen, A.; Nilssen, R.; Nysveen, A. Analytical design of a high-torque flux-switching permanent magnet machine by a simplified lumped parameter magnetic circuit model. In Proceedings of the XIX International Conference on Electrical Machines-ICEM 2010, Rome, Italy, 6-8 September 2010; pp. 1-6.

30. Qi, G.; Chen, J.; Zhu, Z.; Howe, D.; Zhou, L.; Gu, C. Influence of skew and cross-coupling on flux-weakening performance of permanent-magnet brushless AC machines. IEEE Trans. Magn. 2009, 45, 2110-2117. [CrossRef]

31. Zhu, Z.; Shuraiji, A.L.; Lu, Q. Comparative study of tubular partitioned stator permanent magnet machines. In Proceedings of the 2015 Tenth International Conference on Ecological Vehicles and Renewable Energies (EVER), Monte Carlo, Monaco, 31 March-2 April 2015; pp. 1-7.

32. Hua, H.; Zhu, Z.; Zhan, H. Novel consequent-pole hybrid excited machine with separated excitation stator. IEEE Trans. Ind. Electron. 2016, 63, 4718-4728. [CrossRef]

33. Zhao, J.; Guan, X.; Li, C.; Mou, Q.; Chen, Z. Comprehensive evaluation of inter-turn short circuit faults in PMSM used for electric vehicles. IEEE Trans. Intell. Transp. Syst. 2020, 22, 611-621. [CrossRef] 